Check for updates

Hurley Group, London

clare.gerada@nhs.net

Cite this as: BMJ 2021;372:n496

http://dx.doi.org/10.1136/bmj.n496

Published: 23 February 2021
WOUNDED HEALER

\section{Clare Gerada: Loss has become a daily experience in the covid-19 pandemic}

\section{Clare Gerada GP partner}

We are hopefully entering the final straight of this pandemic, and we can begin to take stock of what it has meant to us all. If one word can describe our universal experience it is loss, which has become a daily event.

This might be the loss of a loved one, a colleague, or a friend, or prolonged separation from any of them. It could be the loss of routines, planned celebrations, or formal rites. And we have all experienced loss in our working lives: disrupted training or moving teams, jobs, even hospitals. Among these are less tangible, more ambiguous losses-such as the loss of status when having to move across work boundaries (for example, consultants, used to being in control, have become novices again as they take shifts in intensive care "pronation" teams). We have all experienced a loss of certainty, as none of us can be truly sure of what tomorrow will bring.

Grieving for these losses is difficult in a pandemic. Unlike normal grieving, we cannot easily take time out to recover and recuperate. Instead, almost without exception, we are just carrying on, creating a psychological barrier between how we "really" feel and what we tell others. The stock response, "I'm OK, thanks," translates into, "I feel confused, tired-and, while you're asking, quite distressed."

Our survival techniques such as self-care, going to the gym, attending social events, or connecting with others are not the same when moved online. Those challenges we set for ourselves during the first lockdown-learning a new language, baking bread, or exploring the streets on long walks-have lost their sparkle and just add to our fatigue. Offering solace to patients when we too feel down and in need of comfort is hard, but as doctors we have to give more of ourselves, even when we feel empty.

It's normal to feel sad during these changing times. It's also normal to feel confused about conflicting emotions (also called cognitive dissonance). As doctors, we are in a privileged position. Most of us are still employed. We are still allowed to actually go to work rather than dial into it. Many of us are still engaging in real human contact, albeit often behind plastic visors. Yet we are also exhausted and overwhelmed by our cumulative experiences, and sometimes we just want to be cared for rather than care for others.

This pandemic creates isolation, but we are not alone in our experiences. We are all in this together, and we are all grieving, but it will subside, and some semblance of normality will resume. In the meantime, hang in there-and, if you need to, access the many supports now available to healthcare staff. ${ }^{12}$

Competing interests: See https://www.bmj.com/about-bmj/freelance-contributors.

Provenance and peer review: Commissioned; not externally peer reviewed.

Clare Gerada is chair of Doctors in Distress and medical director of NHS Practitioner Health. Her new book, Beneath the White Coat: Doctors, their Minds and Mental Health, is published by Routledge and can be purchased at https://www.routledge.com/Beneath-the-White-Coat-Doctors-Their-Minds-and-Mental-Health/Gerada/p/book/9781138499737. All royalties will be donated to Doctors in Distress.

NHS Practitioner Health. https://www.practitionerhealth.nhs.uk/.

Doctors in Distress. https://www.doctors-in-distress.org.uk/. 